This item was submitted to Loughborough's Research Repository by the author.

Items in Figshare are protected by copyright, with all rights reserved, unless otherwise indicated.

\title{
Subducted seafloor relief stops rupture in South American great earthquakes: implications for rupture behaviour in the 2010 Maule, Chile earthquake
}

\section{PLEASE CITE THE PUBLISHED VERSION}

http://dx.doi.org/10.1016/j.epsl.2010.07.029

\section{PUBLISHER}

(C) Elsevier B.V.

\section{VERSION}

AM (Accepted Manuscript)

\section{LICENCE}

CC BY-NC-ND 4.0

\section{REPOSITORY RECORD}

Sparkes, Robert, Frederik Tilmann, Niels Hovius, and John K. Hillier. 2019. "Subducted Seafloor Relief Stops Rupture in South American Great Earthquakes: Implications for Rupture Behaviour in the 2010 Maule, Chile Earthquake". figshare. https://hdl.handle.net/2134/13012. 
This item was submitted to Loughborough's Institutional Repository (https://dspace.lboro.ac.uk/) by the author and is made available under the following Creative Commons Licence conditions.

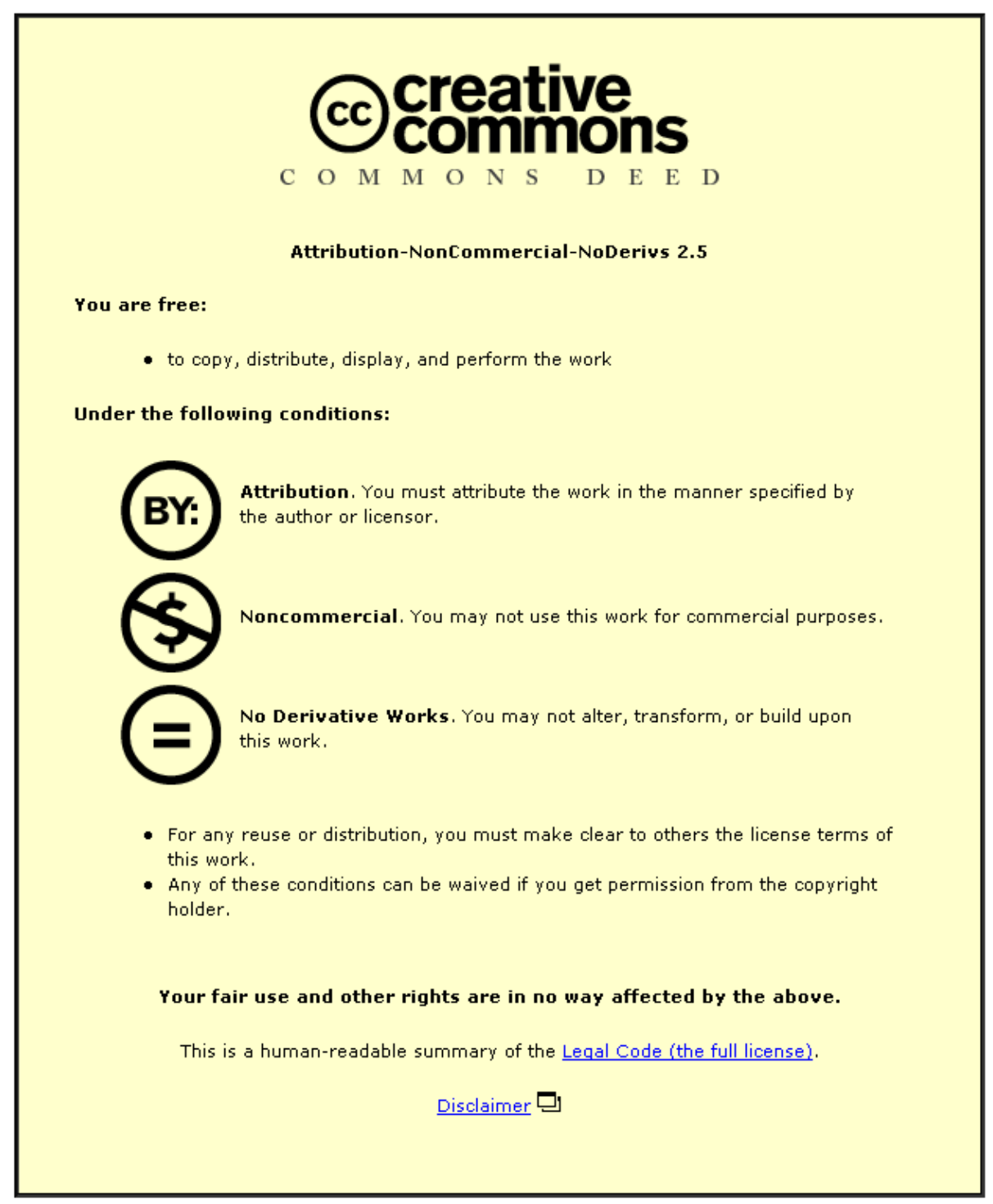

For the full text of this licence, please go to: http://creativecommons.org/licenses/by-nc-nd/2.5/ 
1 Subducted seafloor relief stops rupture in South

2 American great earthquakes: Implications for rupture

3 behaviour in the 2010 Maule, Chile earthquake.

4 Robert Sparkes, Frederik Tilmann, Niels Hovius and John

5 Hillier

6

7 ABSTRACT

8 Great subduction earthquakes cause destructive surface deformation and ground

9 shaking over hundreds of kilometres. Their rupture length is limited by the characteristic strength of the subduction plate interface, and by lateral variations in

11 its mechanical properties. It has been proposed that subduction of topographic features such as ridges and seamounts can affect these properties and stop rupture propagation, but the required relief and physical mechanisms of topographic rupture limitation are not well understood. Here we show that the rupture limits of thirteen historic great earthquakes along the South America-Nazca plate margin are strongly correlated with subducted topography with relief $>1000 \mathrm{~m}$, including the Juan Fernandez Ridge. The northern limit of rupture in the $M_{w} 8.8$ Maule, Chile earthquake of 27 February 2010 is located where this ridge subducts. Analysis of intermediatemagnitude earthquakes shows that in most places the subduction of high seafloor relief creates weak, aseismic zones at the plate interface, which prevent rupture propagation, but that the Juan Fernandez Ridge is associated with a locally strong plate interface. The maximum rupture length, and thus magnitude, of great subduction earthquakes is therefore determined by the size and lateral spacing of topographic features where they are present on the subducting plate. 


\section{Introduction}

26 The amount of displacement in an earthquake is commonly proportional to its rupture

27 length (Wells and Coppersmith, 1994). This determines the area that can be affected by

28 strong ground motion and surface deformation and, where relevant, the amplitude and

29 length scale of associated tsunamis. In most earthquakes, rupture termination is likely

30 to be determined by the energy available for rupture tip propagation along a plane with

31 relatively uniform properties, but for larger potential rupture planes, there is an

32 increased likelihood that mechanical properties vary along the plane. Mechanical

33 heterogeneities could impede rupture tip propagation, or, alternatively, serve as

34 rupture nucleation points. If indeed they exist, these effects may be expected to be

35 most prominent for the largest earthquakes, and they could give rise to segmentation

36 of very long seismogenic fault zones.

37 Globally, great megathrust earthquakes $\left(M_{w} \geq 8.0\right)$ accommodate the majority of 38 shortening along subduction margins. They repeatedly rupture the same margin

39 segments (Beck et al., 1998, Comte et al., 1986), with lengths exceeding the $100 \mathrm{~km}$

40 width of the seismogenic zone. There are indications that rupture termination in great

41 subduction earthquakes could be forced by along-strike variation of properties of the

42 plate interface (Kelleher and McCann, 1976, Sladen, 2009, Bilek, 2010, in press,

43 Loveless et al., 2010, in press). For example, coincidence of some rupture areas of great

44 subduction earthquakes with large negative forearc gravity anomalies along subduction

45 margins has been attributed to localized strong plate interface friction (Song and

46 Simons, 2003, Llenos and McGuire, 2007), and rupture areas have been found to

47 coincide with forearc basins, possibly the surface expression of subduction erosion

48 (Wells et al., 2003, Ranero and von Huene, 2000). However, such forearc features can

49 depend on as well as influence the frictional properties along the plate interface,

50 making it difficult to establish the direction of causality. 
51 Incoming seafloor structures have long been suspected to have an influence on plate 52 interface structure (Cloos, 1992, Scholz and Small, 1997, Bilek et al., 2003). Notably, 53 rupture in the 1946 earthquake along the Nankai trough was deflected around a 54 subducting seamount (Kodaira et al., 2002). This may have been caused by an increase 55 of normal stress, and hence seismic coupling, on the subducted topography (Scholz and 56 Small, 1997), or by the formation of a weak, aseismic area where strain cannot build up 57 (Bilek et al., 2003). Regardless of the mechanism, in the case of subducted seafloor 58 topography the direction of causality is unambiguous. If a correlation between the 59 location of subducted seafloor topography and the extent of earthquake ruptures can 60 be demonstrated then it is clear that the former has influenced the latter by affecting 61 the frictional properties of the plate interface. Although many previous studies have 62 noted the apparent coincidence of incoming seamount chains and earthquake 63 segmentation, the statistical significance of these observations has hitherto not been 64 tested, nor is it clear how large a seamount chain has to be before it can (co-)determine 65 rupture segmentation.

Acknowledging the fact that several other factors may affect rupture propagation along a subduction plate interface, we have sought to isolate and determine the strength and nature of the role of subducted topography in rupture termination in great earthquakes, and the critical size of subducted topography. We have done this by exploring the randomness or otherwise of the collocation of extrapolated seafloor relief, great earthquake rupture limits and patches of subdued background seismicity along the Pacific margin of South America between $12^{\circ} \mathrm{S}$ and $47^{\circ} \mathrm{S}$. On this margin, the Nazca Plate moves eastward at $\sim 65 \mathrm{~mm} / \mathrm{yr}$ relative to, and is subducted under South America (Angermann et al., 1999). Large sections of the Nazca Plate have smooth seafloor with topographic relief $<200 \mathrm{~m}$, but elsewhere seamount chains with varying relief of up to $3.5 \mathrm{~km}$ are carried into the subduction trench, enabling a quantitative 
exploration of the effect of subducting topography on seismicity. Since 1868, 15 great earthquakes have occurred along the Nazca margin (See Fig. 1 and Table 1), including the largest recorded earthquake, $M_{w} 9.5$ in 1960 . These earthquakes had rupture lengths from 150 to 1,050 km. On 27 February 2010, a 600 km section of the Nazca margin ruptured in the $M_{w} 8.8$ Maule earthquake. Here, we demonstrate that the sustained subduction of seafloor features with relief in excess of $\sim 1.0 \mathrm{~km}$ has systematically stopped rupture in these historic great earthquakes on the Nazca margin. We argue that in most cases rupture termination is due to the creation of weak, aseismic zones in the plate interface. In addition, we explore the possible causes of rupture termination in the 2010 Maule earthquake. It has not been our intention to carry out a global survey of subduction margins, but although the critical height of subducted topography may vary between settings, its role in stopping earthquake rupture is likely to be similar along the Nazca margin and elsewhere.

\section{Constraints on Rupture Zones and Subducting Topography}

Subduction zone earthquakes with $\mathrm{M}_{\mathrm{w}}<8.0$ tend to rupture distances less than $100 \mathrm{~km}$ and their rupture zones have aspect ratios close to one. As $100 \mathrm{~km}$ is comparable to the width of the seismogenic zone, the endpoints of these major but not great earthquakes cannot tell us whether there are features along strike that may have stopped their rupture. Whilst some $M_{w}$ 7-7.9 earthquakes have ruptured larger distances, in the interest of consistency we have restricted our study to $M_{w}>8.0$, as these great events should all have ruptured the plate interface over more than $100 \mathrm{~km}$ in the trenchparallel direction, making it possible to identify parts of the plate interface that may have acted as a barrier or nucleation point for earthquake rupture. Earthquakes with $M_{w}<8.0$ will be considered in the discussion section. 
101 The anecdotal record of very large earthquakes along the Nazca margin stretches back

102 to at least 1575 (Cisternas et al., 2005), but events before 1868 are insufficiently

103 documented to determine the extent of their rupture zones in any detail. Since that

104 year, 15 earthquakes with estimated moment magnitude $M_{w} \geq 8.0$ have occurred on the

105 margin. For events prior to 1973, rupture zones have been determined from damage

106 intensity and co-seismic subsidence (Kelleher, 1972, Spence et al., 1999, Cisternas et al.,

107 2005), and we have used published estimates (see Table 1), with the exception of the

$1081908 M_{w} 8.0$ earthquake offshore Peru, which is insufficiently documented to be

109 included in this study. After 1973, rupture zones can be constrained from aftershock

110 locations (Wells and Coppersmith, 1994, USGS NEIC catalog). We have done this for all

111 recent great earthquakes, including the 2010 Maule event. Uncertainty in the mapping

112 of rupture zones is due to the gradual decrease of slip toward the rupture tip, and the

113 imperfect correlation between the rupture zone and the distribution of aftershocks,

114 seismic intensities and co-seismic subsidence. The resulting uncertainty is less than 50

$115 \mathrm{~km}$ (Kelleher, 1972), and rupture limits determined from aftershock observations match

116 other published rupture area estimates (Comte et al., 1986, Delouis et al., 1997,

117 Sobesiak, 2000, Tavera et al., 2002) to within $40 \mathrm{~km}$. Our findings are therefore not

118 sensitive to the exact method of defining rupture zones, and this uncertainty cannot be

119 easily reduced for historical earthquakes.

120 Seafloor topography was constrained from the TOPEX global seafloor bathymetry

121 dataset (Smith and Sandwell, 1997), which is created from satellite altimetry. This

122 dataset was chosen for its consistent derivation of the depth both along the margin and

123 in the open ocean, and for its inclusion of seamounts unmeasured by sonic soundings,

124 but the accuracy of seamount heights may be $\pm 100 \mathrm{~m}$ or more (Marks and Smith,

125 2007). We have calculated seafloor relief by taking the difference between the depth at

126 a point and the mean depth of the seafloor within a radius of $3^{\circ}$, which is generally 
127

128

129

130

131

132

133

134

135

136

137

138

139

140

141

142

143

$\sim 4000 \mathrm{~m}$. The Nazca Plate has prominent topographic features with positive relief $>400$ m, including the Nazca Ridge (Spence et al., 1999), which has relief of up to $3500 \mathrm{~m}$, and several seamount chains with approximately linear trends for $>500 \mathrm{~km}$ extending to the subduction zone. Assuming some continuity of seamount chain formation through time, it is likely that associated topography has already subducted and interfered with the plate interface. However, independent evidence of subducted relief (Kodaira et al., 2002) only exists in isolated locations such as the subducted Papudo seamount along the extension of the Juan Fernandez Ridge (von Huene et al., 1997). Where we have found three or more topographic features with relief above a threshold value to align we have extrapolated their assumed linear trend into the subduction zone, taking into account offsets on known fracture zones. Moreover, we have assumed that in this case a topographic feature of a magnitude similar to that of the visible seafloor topography has already entered the subduction zone. The validity of this assumption can only be tested with targeted seismic surveys. The shallow dip of the seismogenic plate interface, $\sim 18^{\circ}$ on average (Tichelaar and Ruff, 1991), makes a correction for dip unnecessary near the plate boundary. Positive relief on the Nazca seafloor was contoured at $200 \mathrm{~m}$ intervals upward of $400 \mathrm{~m}$, and contours were extrapolated into the subduction zone by projecting the widest parts of identified topography. Likely locations of subducted relief are shown in Figures 1 and 2.

\section{Collocation of subducted topography and earthquake rupture endpoints}

Rupturing in historical great earthquakes repeatedly arrested at $32^{\circ} \mathrm{S}$ and $15^{\circ} \mathrm{S}$, on the subducted Juan Fernandez Ridge (JFR) and the Nazca Ridge respectively (Fig. 2). These ridges comprise the largest positive relief on the Nazca Plate. Other rupture limits are associated with subducted topography at $20^{\circ} \mathrm{S}, 25^{\circ} \mathrm{S}$ and $47^{\circ} \mathrm{S}$. Specifically, 11 out of the 
15226 rupture limits in well documented great earthquakes were within $40 \mathrm{~km}$ of a zone

153 with inferred subducted relief $>1000 \mathrm{~m}$, although only $\sim 22 \%$ of the studied margin is

154 within this distance. Whilst it has been possible for great earthquake ruptures to be

155 located entirely between zones with high subducted relief (e.g., the 1939 event at $35^{\circ}-$

$\left.15637^{\circ} \mathrm{S}\right)$, rupture zones generally do not appear to have crossed subducted relief $>1000 \mathrm{~m}$,

157 with only one exception, the 1922 event which traversed an assumed obstruction at $15828^{\circ} \mathrm{S}$.

159 To test the statistical significance of our observations, we have compared the 160 distribution of historical rupture zones with simulated patterns of rupture zones along 161 the margin. Using a Monte Carlo approach, and observing that even in the absence of 162 any subducted relief rupture limits from neighbouring earthquakes tend to collocate, 163 forming subduction zone segments (Beck et al., 1998), we have concatenated the 164 rupture lengths of the thirteen sufficiently constrained historical earthquakes (not 165 including the 2010 Maule earthquake), locating the first earthquake randomly along 166 the South American margin, and repeating 2000 times. Two scenarios, representing 167 end-member hypotheses for earthquake-topography interaction, were applied. In the 168 first, 'unconstrained' scenario, subducted topography has no effect on rupture 169 propagation. In this scenario, the next rupture in a sequence was started at the limit of 170 the preceding earthquake.

171 This process was repeated to link 13 rupture zones, with rupture zone limits lying in 172 nearby-pairs. The total length of this group exceeds the length of the margin along 173 which the actual earthquakes occurred, due to overlap of ruptures over the record 174 interval. Simulated rupture limits outside the geographic range of the historic 175 earthquakes $\left(12^{\circ} \mathrm{S}-47^{\circ} \mathrm{S}\right)$ were discarded, and equal coverage along the margin was 176 maintained. Note that proximity of rupture limits is a feature shared by most, but not 
177 all actual earthquake rupture zones (see Figure 2). Pairs of neighbouring rupture ends

178 are a natural consequence of a segmented subduction zone in which earthquakes do

179 not generally have overlapping rupture zones, irrespective of the mechanism of the 180 segmentation.

181 In the second, 'constrained' scenario, rupture was stopped by subducted relief of a 182 given minimum size $H_{\min }$. The next earthquake rupture zone was located immediately 183 beyond this relief. Relocated rupture limits were scattered at random within $50 \mathrm{~km}$ of 184 the restricting topographic feature to represent the uncertainty of the actual 185 observations. The alternative that earthquake rupture starts rather than stops on high 186 subducted topography is not explored in detail for reasons given in the discussion, 187 below.

188 If subduction of high standing seafloor topography has an effect on earthquake rupture 189 propagation, then this effect may act some distance from the subducted feature, and 190 the apparent width of a feature varies with $H_{\min }$. To account for this, and for the 191 uncertainty in the rupture endpoint location, we have varied the search distance $S_{D}$ 192 within which earthquake rupture endpoints are deemed to be associated with 193 subducted topography. For a given search distance $S_{D}$ and $H_{\min }$, the simulation routine 194 was repeated 2,000 times, generating a total of 26,000 earthquakes. The number of 195 rupture limits for a specified $S_{D}$ was normalized for comparison with the 26 limits of 196 historic rupture zones. $S_{D}$ was varied in steps of $5 \mathrm{~km}$. $H_{\min }$ was varied in $200 \mathrm{~m}$ 197 increments.

198 Historical data plot between the average results simulated for the constrained and 199 unconstrained scenarios, and are close to the results of the constrained model at 200 moderate relief, $800-1200 \mathrm{~m}$, and search distances of $35-45 \mathrm{~km}$ (Fig. 3 a,b). This 
201

202

203

204

205

206

207

208

209

\section{0}

211

suggests that along the Nazca margin, features larger than $800 \mathrm{~m}$ commonly stop earthquake rupture propagation, and agrees with anecdotal observations.

An alternative test procedure, using earthquakes with $M_{w} \geq 8.0$ sampled randomly from the logarithmic Gutenberg-Richter relationship between earthquake magnitude and frequency rather than the historical earthquake catalogue, and assigning rupture area according to a common earthquake magnitude-length scaling law (Wells and Coppersmith, 1994), has yielded comparable results (supplementary information). A further alternative in which earthquakes were distributed individually rather than being linked together also produced equivalent findings.

\section{Statistical significance of collocation}

The collocation of historical rupture limits with subducted topography has not arisen by chance, according to a statistical significance test based on the probability density function of the distribution of simulated unconstrained earthquakes. In this test, we have determined the probability $P$ that the number of rupture limits located within a given search distance $S_{D}$ from subducted topography of a given size $H$ for randomly positioned, unconstrained earthquakes exceeds the number of historical rupture limits that meet the same criteria.

Our underlying assumption is that the number of rupture limits falling randomly near topographic features $\left(N_{\mathrm{uc}}\right)$ can be determined directly from the unconstrained distribution of rupture zones. Within groups of 26 simulated earthquake limits $\left(N_{\text {total }}\right)$, those within a given distance of subducted topography were counted, and their probability function $\mathbf{P}\left(N_{u c} \geq N_{\text {real }}\right)$ was determined. The probability of the unconstrained simulation $\left(N_{\mathrm{uc}}\right)$ having at least as many rupture limits near significant topography as the actual data $\left(N_{\text {real }}\right)$ is given by: 


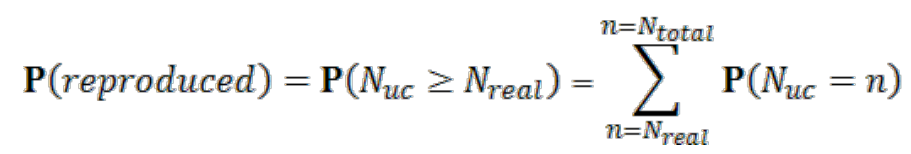

226 Figure $3 c$ shows a diagonal region in $\mathrm{S}_{D}-\mathrm{H}_{\min }$ space in which correlation is strongest

227 between relief and rupture endpoints. This is because increasing $S_{D}$ and $H_{\min }$

228 concurrently causes the same area of the margin to be considered. The minimum relief

229 at which subducted features affect the location of rupture limits is equivalent to the

230 lowest relief within this domain of significant correlation. At this relief the number of

231 subducted topographic features included is maximal, and $S_{D}$ smallest, without adverse

232 effect on the correlation.

233 For $H>1000 \mathrm{~m}$ and $S_{D}=40 \mathrm{~km}$, rupture limits and subducted topography are 234 significantly correlated, with $\mathrm{P}=1.4 \%$ (Fig. 3c). Note that no features have a maximum 235 positive relief between $800 \mathrm{~m}$ and $1200 \mathrm{~m}$. This limits the precision with which we can 236 define critical relief for rupture collocation. Relief $>1000 \mathrm{~m}$ admits the same number of 237 subducted features as $>800 \mathrm{~m}$, but the additional width of features caused by using the 238 lower threshold does not increase the amount of collocation.

239 Subducted relief $<800 \mathrm{~m}$ does not appear to stop or start earthquake rupture 240 propagation. The Nazca plate has much topography with relief of $400-800 \mathrm{~m}$, but at $S_{D}$

$241=40 \mathrm{~km}, P=4.3 \%$ for $H>800 \mathrm{~m}$, whereas $P$ increases to $28 \%$ for $H>400 \mathrm{~m}$, indicating

242 the absence of significant correlation at this relief threshold. Nevertheless, subduction

243 of topography $<800 \mathrm{~m}$ may still affect the slip distribution in particular earthquakes 244 (Kodaira et al., 2002).

\section{Discussion}

246 Collocation of subducted topography and rupture limits could arise from rupture

247 initiation or termination. Assuming that the epicenter location denotes the initiation of 
rupture, it can be determined whether topography starts or stops great earthquakes. Six out of thirteen studied earthquakes had epicenters within $40 \mathrm{~km}$ of topography with $\mathrm{H}>1000 \mathrm{~m}$, whilst $\sim 22 \%$ of the margin lies within this distance (See Fig. 2 ). The chance of this occurring at random is $22 \%$, according to an analysis of the synthetic distribution of epicenters, equivalent to the analysis of endpoints summarized above. This correlation is much weaker than the match between rupture endpoints and topography. None of the six events have rupture zones which cross subducting topography, but in all rupture has extended away from the topography. Hence, the subduction of seafloor relief $>800-1000 \mathrm{~m}$ is likely to impede or stop earthquake rupture, even if rupture nucleated on or near to that topography.

In the absence of significant subducting topography, earthquake rupture may be stopped by other factors, either structural (e.g. forearc structure or geometry of the slab) or because there is insufficient release of energy to propagate the rupture tip, even in the absence of any structural changes. In fact, for all of the 14 earthquakes considered here at least one of the endpoints was not close to subducted topography.

Effective and continued rupture arrest by subduction of high standing seafloor topography may require topographic features to be spaced at less than the width of the seismogenic zone. Along the Nazca margin, the width of this zone is $\sim 100 \mathrm{~km}$. Greater separation between topographic features of sufficient size within an alignment could leave gaps in the barrier to rupture propagation. This may be the case for the seamount chain at $28^{\circ} \mathrm{S}$ where features with relief $>1000 \mathrm{~m}$ are up to $200 \mathrm{~km}$ apart. Its trend was crossed by the 1922 great earthquake, the only such traverse on record.

According to our findings it is likely that there is a causal link between subducted topography and great earthquake rupture limits. Along-margin rupture could be stopped by subducted topography either because it forms a strongly coupled patch 
273 within the seismogenic zone (Scholz and Small, 1997), too strong to break in the 274 rupture, or because it forms a weak, aseismic patch (Bilek et al., 2003) which has no 275 stored strain to release. Assuming that the long-term rate of shortening is uniform 276 along the subduction margin, the local strength of the plate interface affected by 277 subduction of topography may be reflected in the seismic moment release between 278 great earthquakes, when these patches are expected to catch up with slip elsewhere 279 along the margin. Strong patches are likely to have a relatively high rate of seismic moment release in small and intermediate size earthquakes in these intervals. Weak patches cannot accumulate elastic strain and are expected to have subdued background seismicity.

We have calculated the cumulative moment release between great earthquakes over 28435 years since 1973, including all shallow, intermediate size earthquakes (depth<50 km, $285 M_{w}$ 5.0-7.9) within a $0.5^{\circ}$ moving window, but excluding aftershocks within two months 286 of a great earthquake, as well as the largest intermediate event in each zone, which 287 results in a more robust estimate (Frohlich, 2007) (Fig. 2). Five of six locations along the 288 margin with subducted topography $>1000 \mathrm{~m}$ have low background moment release. 289 Instead, substantial background moment release tends to be concentrated at great 290 earthquake rupture limits away from subducted topography, showing that segment 291 boundaries do have residual strain and that subducting topography changes the way in 292 which this is released. The anti-correlation of tall subducted topography and maxima of 293 intermediate seismicity indicates that this topography usually acts to weaken the plate 294 interface, promoting aseismic deformation and hence impeding earthquake rupture 295 along the margin. Weak interplate coupling associated with subducted topography has 296 been observed for the Nazca Ridge (Perfettini et al., 2010) and in Japan (Mochizuki et 297 al., 2008). 


\section{Mw 8.8 Maule, Chile Earthquake}

299 Along the Nazca margin there is one exception to the collocation of subducted, high

300

301

302

303

304

305

306

307

308

309

310

311

312

313

314

315

316

317 seafloor topography and minimum background seismicity. At $32^{\circ} \mathrm{S}$, potentially very tall $(>2 \mathrm{~km})$ subducted topography of the JFR coincides with a peak in background seismicity (Fig. 2). This location is of special interest because it is where northward rupture propagation in the 2010 Maule earthquake arrested. The hypocenter of this earthquake was located offshore at $35.8^{\circ} \mathrm{S}, 72.7^{\circ} \mathrm{W}$, at an estimated depth of $\sim 38 \mathrm{~km}$, with a thrust mechanism, striking at $18^{\circ} \mathrm{N}$, parallel to the margin and dipping $18^{\circ}$ to the east (USGS NEIC Catalog). Aftershock locations indicate that the earthquake ruptured the Nazca margin over a length of $\sim 600 \mathrm{~km}$ (Fig. 1), occupying a known seismic gap (Ruegg et al., 2002). Along the South American margin, its rupture length was exceeded in historical times only in the $1960 \mathrm{M}_{\mathrm{w}} 9.5$ earthquake. Rupture extended northward to $33.1^{\circ} \mathrm{S}$, overlapping the 1906 and 1985 rupture zones and stopping within $22 \mathrm{~km}$ of the subducted JFR. Although this is consistent with our finding that subducted topography $>1,000 \mathrm{~m}$ is likely to stop rupture propagation, we believe that it is the presence of a strong patch in the plate interface, borne out by high intermediate seismicity at this location, rather than the weakening effect of subduction of seafloor topography that has arrested northward rupture propagation in 2010. Uniquely, this is also the location of a subducted fracture zone, a change in the gradient of the subducted slab (Barazangi and Isacks, 1976), and a transition from a sediment filled to starved trench with an associated change from subduction accretion to subduction erosion (Bangs and Cande, 1997). High background moment release at $32^{\circ} \mathrm{S}$, and the elevated plate interface strength it implies are likely to be the compound effect of all these factors, indicating that the weakening effect of subduction of high seafloor topography can be drowned out by strengthening due to other asperities. 
323 Rupture in the Maule earthquake propagated southward to $38.6^{\circ} \mathrm{S}$, unimpeded by

324 significant subducted topography. At its southern limit, the 2010 rupture area overlaps

325 the northern edge of the 1960 rupture area, indicating that the earlier earthquake may

326 not have released all stress in this area. The southern rupture limit coincides with a

327 large peak in background seismicity, a pattern found in at least eight historic great

328 earthquakes on the Nazca margin (Fig. 2).

\section{Conclusions}

330 Along the South American Nazca margin rupturing in great earthquakes is likely to be

331 impeded by subducted topography with positive relief $>1000 \mathrm{~m}$, engaged in the 332 seismogenic part of the plate interface. In general, this appears to be due to mechanical 333 weakening of the plate interface, thus preventing the buildup of stresses required for 334 the propagation of very large earthquakes. This effect may require the actual presence 335 of a topographic feature within the seismogenic zone, and could dissipate after the 336 feature has been transported through this zone. On the subducted Juan Fernandez 337 Ridge it may be overprinted by other factors that have strengthened the plate interface 338 sufficiently to arrest rupturing in the 2010 Maule earthquake. Along margin sections 339 with subducted relief $<800 \mathrm{~m}$, rupturing in historical great earthquakes has been 340 unimpeded. The length of such sections may impose an upper bound on the possible 341 earthquake size, limiting hazard in some places. If this is true, then the largest 342 earthquakes between the intersections of the Nazca and Juan Fernadez ridges and the 343 South America plate margin will have rupture lengths no larger than $550 \mathrm{~km}$ 344 (equivalent $M_{w} 9.1$ ). In contrast, rupture could be unimpeded between the JFR and the

345 Chile Rise, over a length of $1,450 \mathrm{~km}$, enabling an earthquake rupture $33 \%$ longer than 346 in the $1960 \mathrm{M}_{\mathrm{w}} 9.5$ event on this segment of the Nazca margin. 
Angermann, D., Klotz, J. and Reigber, C. Space-geodetic estimation of the Nazca-South America Euler vector, 1999. Earth Planet. Sci. Lett. 171, 329-334.

Bangs, N. L. and Cande S.C., 1997. Episodic development of a convergent margin inferred from structures and processes along the southern Chile margin, Tectonophys.16, 489-50

Barazangi, M. and Isacks, B. L., 1976. Spatial distribution of earthquakes and subduction of the Nazca plate beneath South America, Geology 4, 686-692.

Beck, S. L., Barrientos, S., Kausel, E. and Reyes, M. Source characteristics of historic earthquakes along the central Chile subduction zone, 1998. J. South Am. Earth Sci. 11, 115-129.

Bilek, S. L., Schwartz, S. Y. and DeSchon, H. R., 2003. Control of seafloor roughness on earthquake rupture behavior. Geology 31, 455-458.

Bilek, S. L., in press. Seismicity along the South-American subduction zone: Review of large earthquakes, tsunamis, and subduction zone complexity. Tectonophysics, doi: 10.1016/j.tecto.2008.02.037

Cisternas, M., Atwater, B.F., Torrejon, F., Sawai, Y., Machuca, G., Lagos, M., Eipert, A., Youlton, C., Salgado, I., Kamataki, T., Shishikura, M., Rajendran, C.P., Malik, J.K., Rizal, Y., and Husni, M., 2005. Predecessors of the giant 1960 Chile earthquake. Nature 437.

Cloos, M., Thrust-type subduction zone earthquakes and seamount asperities: A physical model for seismic rupture, 1992. Geology, 20, 601-604.

Comte, D., Eisenberg, A., Lorca, E., Pardo, M., Ponce, L., Saragoni, R., Singh, S.K., and Súarez, G., 1986. The 1985 central Chile earthquake: a repeat of previous great earthquakes in the region? Science, 233, 449-453.

Delouis, B., Monfret, T., Dorbath, L., Pardo, M., Rivera, L., Comte, D., Haessler, H., Caminade, J.P., Ponce, L., Kausel, E., and Cisternas, A., 1997. The $M_{w}=8.0$ Antofagasta (northern Chile) earthquake of 30 July 1995: a precursor to the end of the large 1877 gap. Bull. Seismol. Soc. Am. 87, 427-445.

Frohlich, C., 2007. Practical suggestions for assessing rates of seismic-moment release. Bull. Seismol. Soc. Am. 97, 1158-1166.

Kelleher, J.A., 1972. Rupture zones of large South American earthquakes and some predictions. J. Geophys. Res. 77, 2087-2103.

Kelleher, J. A. and McCann, W., 1976. Buoyant zones, great earthquakes, and unstable boundaries of subduction. J. Geophys. Res. 81, 4885-4896.

Kodaira, S., Kurashimo, E., Park, J.-O., Takahashi, N., Nakanishi, A., S., M., Iwasaki, T., Hirata, N., Ito, K., and Kaneda, Y., 2002. Structural factors controlling the rupture 
process of a megathrust earthquake at the Nankai trough seismogenic zone. Geophys. J. Int. 149, 815-835.

Llenos, A. L. and McGuire, J. J., 2007. Influence of fore-arc structure on the extent of great subduction zone earthquakes. J. Geophys. Res. 112, B09301.

Loveless, J. P., Pritchard, M. E. and Kukowski, N., in press. Testing mechanisms of subduction zone segmentation and seismogenesis with slip distributions from recent Andean earthquakes. Tectonophysics doi:10.1016/j.tecto.2009.05.008

Marks, K. M. and Smith, W. H. F., 2007. Some remarks on resolving seamounts in satellite gravity. Geophys. Res. Lett. 34.

Mochizuki, K., Yamada, T., Shinohara, M., Yamanaka, Y. and Kanazawa, T., 2008. Weak interplate coupling by seamounts and repeating $M \sim 7$ earthquakes. Science 321, 11841197.

Perfettini, H., Avouac, J-P., Tavera, H., Kositsky, A., Nocquet, J-M., Bondoux, F., Chileh, M., Sladen, A., Audin, L., Farber, D. L., and Soler, P., 2010. Seismic and aseismic slip on the Central Peru megathrust. Nature 465.

Ranero, C. R. and von Huene, R., 2000. Subduction erosion along the Middle America convergent margin. Nature 404, 748-752.

Ruegg, J. C., Campos, J., Madariaga, R., Kausel, E., de Chabelier, J.B., Armijo, R., Dimitrov, D., Georgiev, I., and Barrientos, S., 2002. Interseismic strain accumulation in south central Chile from GPS measurements, 1996-1999. Geophys. Res. Lett. 29, 12-1-4.

Scholz, C. H. and Small, C., 1997. The effect of seamount subduction on seismic coupling. Geology 25, 487-490.

Sladen, A., Tavera, H., Simons, M., Avouac, J.P., Konca, A.O., Perfettini, H., Audin, L., Fielding, E.J., Ortega, F., and Cavagnoud, R., 2009. Source model of the $2007 \mathrm{Mw} 8.0$ Pisco, Peru earthquake: Implications for seismogenic behavior of subduction megathrusts. J. Geophys. Res. 115, B02405.

Smith, W. H. F. and Sandwell, D. T., 1997. Global sea floor topography from satellite altimetry and ship depth soundings. Science 277.

Sobiesiak, M.M., 2000. Fault plane structure of the Antofagasta, Chile earthquake of 1995. Geophys. Res. Lett. 27, 581-584.

Song, T-R. A. and Simons, M., 2003. Trench-parallel gravity variations predict seismogenic behaviour in subduction zones. Science, 301, 630-633.

Spence, W., Mendoza, C., Engdahl, E. R., Choy, G.L. and Norabuena, E., 1999. Seismic subduction of the Nazca Ridge as shown by the 1996-97 Peru earthquakes. Pure Appl. Geophys. 154, 753-776.

Tavera, H., Buforn, E., Bernal, I., Antayhua, Y. and Vilacapoma, L., 2002. The Arequipa (Peru) earthquake of June 23, 2001. J. Seismol. 6, 279-283. 
448 Tichelaar, B. W. and Ruff, L. J., 1991. Seismic coupling along the Chilean subduction

449 margin. J. Geophys. Res. 96, 11997-12022.

USGS NEIC catalog: http://earthquake.usgs.gov/earthquakes/eqarchives/epic/

von Huene, R., and 47 coauthors, 1997. Tectonic control of the subducting Juan

Wells, E. L. and Coppersmith, K.J., 1994. New empirical relationships among magnitude, rupture length, rupture width, rupture area, and surface displacement. Bull. Seismol. Soc. Am. 84, 974-1002. centered asperities in great subduction zone earthquakes: A link between slip, subsidence and subduction erosion? J. Geophys. Res. 10, 2507-2536. 
465 epicenters plot outside identified rupture zones, this is likely due to inaccuracies in locating earthquakes

466 before the global installation of seismometers. Areas with more than $1000 \mathrm{~m}$ relief are marked on

467 shaded seafloor topography. Black dots and lines show the inferred location of subducted topographic

468 highs, grey regions show the area within $\mathbf{5 0} \mathrm{km}$ of these highs. Inset: Detailed view of the area of the 27

469 February 2010 Maule earthquake. Red dots show aftershocks between February 27 and March 8, with

470 size scaled by magnitude. 
473 Figure 2: Latitudinal distribution of seismicity and subducted relief along Nazca margin. Earthquake

474 rupture zones and epicenters are shown as black bars and white stars, respectively; thin black line is

475 seismic moment release in $M_{w}<8.0$ earthquakes at depths less than $50 \mathrm{~km}$ since $1973\left(0.5^{\circ}\right.$ moving

476 windows). Also shown are areas with inferred subducted seafloor relief, binned at $200 \mathrm{~m}$ vertical

477 intervals. Grey bars mark areas with likely subducted relief $>1000 \mathrm{~m}$, transposed to the upper axes for

478 comparison. An exception to separation of relief and moment release is the JFR at $32^{\circ} \mathrm{S}$.

479 
481 simulated earthquake distributions. Circles show limits of 13 actual earthquake ruptures. Triangles and

482 squares show results for simulations in which rupture limits are/are not constrained by subducted seafloor features, respectively. Synthetic results are based on 2000 runs with 13 earthquakes each. A) Number of earthquake limits within search distance from (inferred) subducted seafloor relief $>1000 \mathrm{~m}$. B) Number of earthquake ruptures within $\mathbf{4 0 ~} \mathrm{km}$ of (inferred) subducted seafloor relief of varying size. Error bars denote the inter-quartile range of the synthetic results. Note how the plot of observed earthquake rupture limits approaches that of topographically constrained, synthetic ruptures. C) Probability of the observed correlation of earthquake rupture limits and subducted seafloor relief being reproduced by chance by an unconstrained synthetic distribution. Strongest topography - rupture limit correlation (marked in white) occurs between 1000 - 1600m relief and $40-80 \mathrm{~km}$ search distance. The increasing relief narrows admitted topographic features, reducing the area searched for a given $S_{D}$. 
Figure 1

Click here to download high resolution image

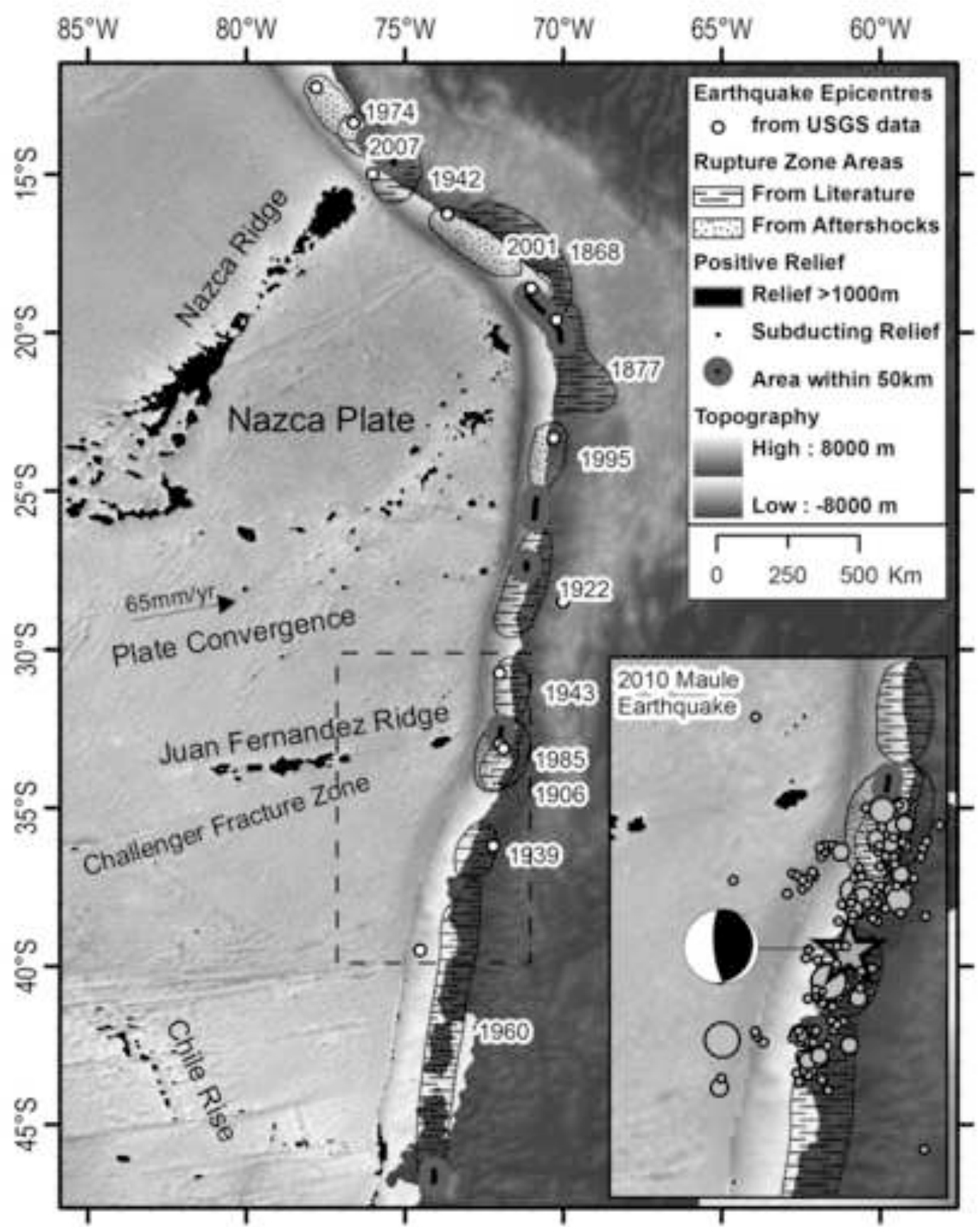




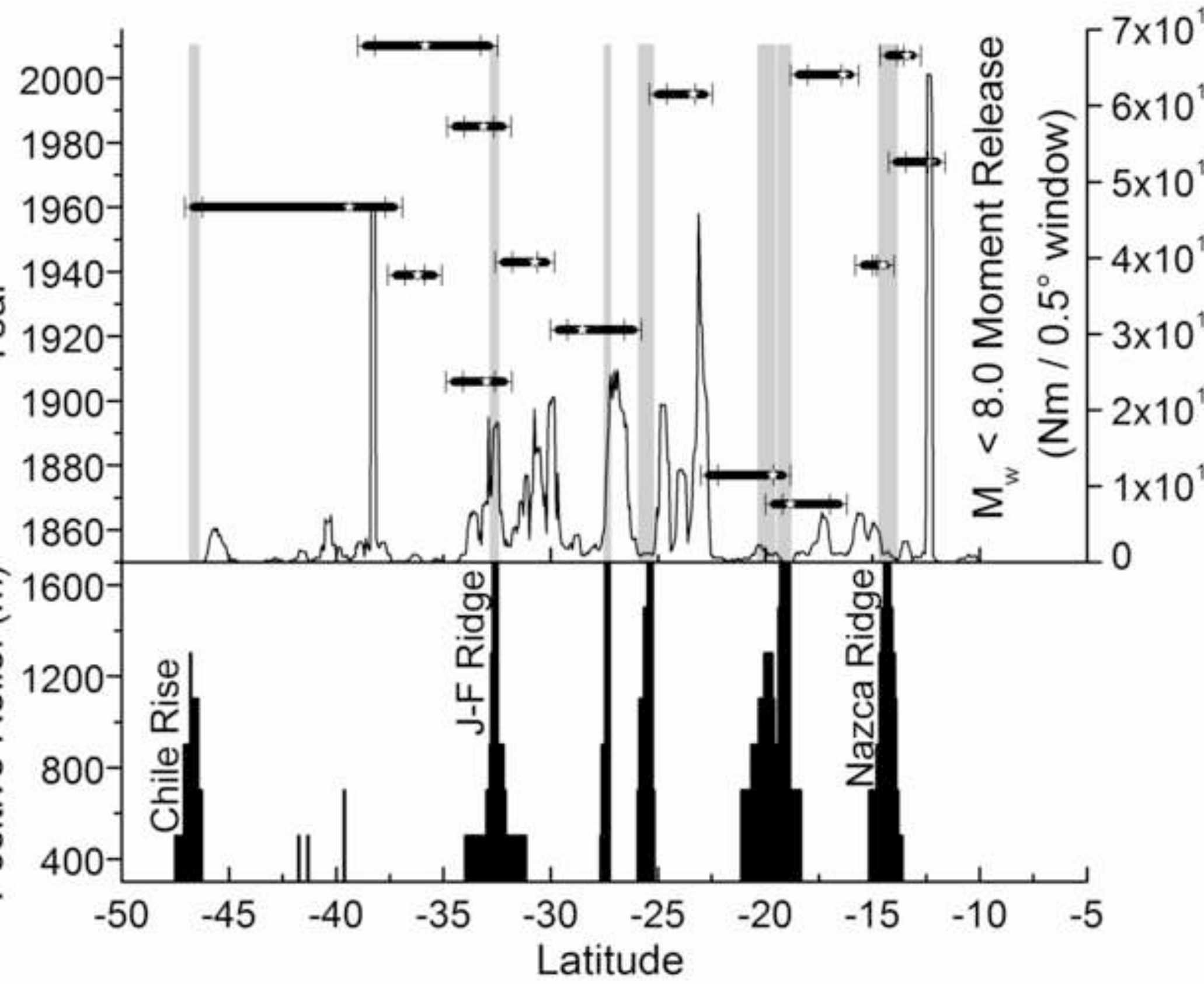



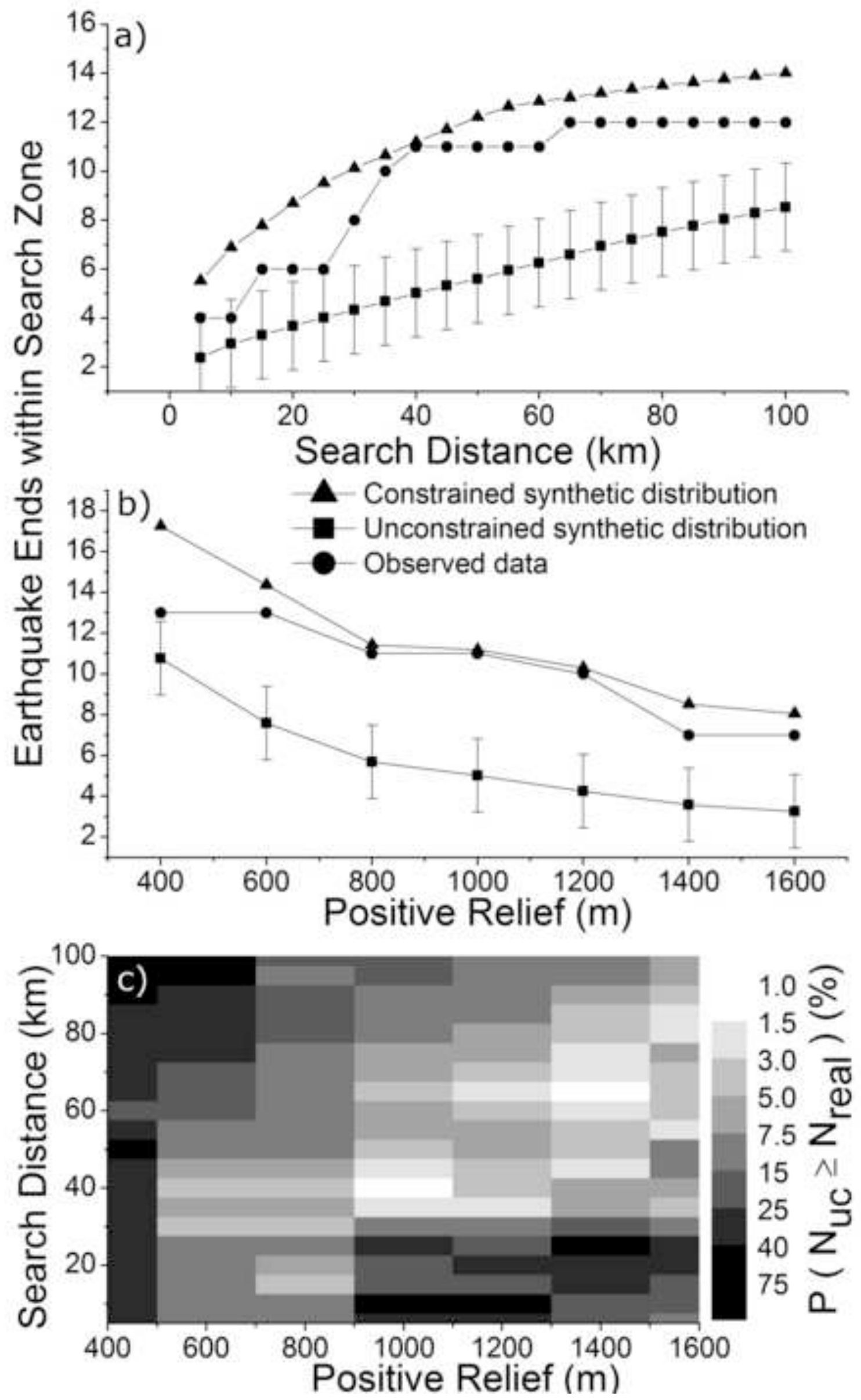
Table 1

Click here to download Table: Table1.xls

\begin{tabular}{|c|c|c|c|c|c|}
\hline Date & Source & $\begin{array}{c}\text { Alternate rupture } \\
\text { zone estimation }\end{array}$ & Location & $\begin{array}{c}\text { Magnitud } \\
\mathbf{e}\end{array}$ & $\begin{array}{c}\text { Length } \\
(\mathbf{k m})\end{array}$ \\
\hline $13 / 08 / 1868$ & Spence 1999 & & Southern Peru & 8.8 & 400 \\
\hline $10 / 05 / 1877$ & Spence 1999 & & Northern Chile & 8.8 & 400 \\
\hline $8 / 17 / 1906$ & Kelleher 1972 & & Central Chile & 8.6 & 250 \\
\hline $11 / 11 / 1922$ & Kelleher 1972 & & Central Chile & 8.4 & 390 \\
\hline $1 / 25 / 1939$ & Kelleher 1972 & & Southern Chile & 8.2 & 190 \\
\hline $8 / 24 / 1942$ & Kelleher 1972 & & Central Peru & 8.6 & 150 \\
\hline $4 / 6 / 1943$ & Kelleher 1972 & & Central Chile & 8.3 & 210 \\
\hline $5 / 22 / 1960$ & Cisternas 2005 & & Southern Chile & 9.5 & 1050 \\
\hline $10 / 3 / 1974$ & Aftershocks & & Central Peru & 8 & 280 \\
\hline $3 / 3 / 1985$ & Aftershocks & Comte 1986 & Central Chile & 8 & 250 \\
\hline $8 / 1 / 1995$ & Aftershocks & Delouis 1997, & Northern Chile & 8 & 240 \\
& & Sobesiak 2000 & & & \\
\hline $6 / 23 / 2001$ & Aftershocks & Tavera 2001 & Southern Peru & 8.4 & 360 \\
\hline $8 / 15 / 2007$ & Aftershocks & & Central Peru & 8 & 160 \\
\hline
\end{tabular}


Supplementary Information:

Gutenberg-Richter distribution

As well as generating earthquake distributions using the rupture lengths from measured earthquakes, rupture lengths were assigned at random according to the logarithmic GutenbergRichter magnitude relationship. Earthquake magnitudes were converted into lengths using scaling factors based on the earthquake moment. Lengths varied from $100 \mathrm{~km}$ at magnitude 8.0 up to an artificially limited maximum rupture length of $1000 \mathrm{~km}$ at $\mathrm{Mw} 9.5$ and above due to the lack of naturally-occurring earthquakes existing above this length.

After determining the rupture length, the synthetic earthquake rupture procedure continued as before, placing earthquakes in groups of 13 and rupturing these in sequence along the subduction margin. Earthquakes end points were allowed to rupture unrestricted, or to be restricted by projected subducting topographic features.

The results are similar to those obtained using the measured earthquake rupture zone lengths. At low relief, there is no correlation between rupture endpoints and topography, the observed number of rupture endpoints near to topography is reproducible by random positioning of synthetic endpoints. At moderate topographic heights $(1000-1200 \mathrm{~m})$ there is good correlation between rupture zone endpoints and a zone up to $\sim 50 \mathrm{~km}$ away from the topography. 

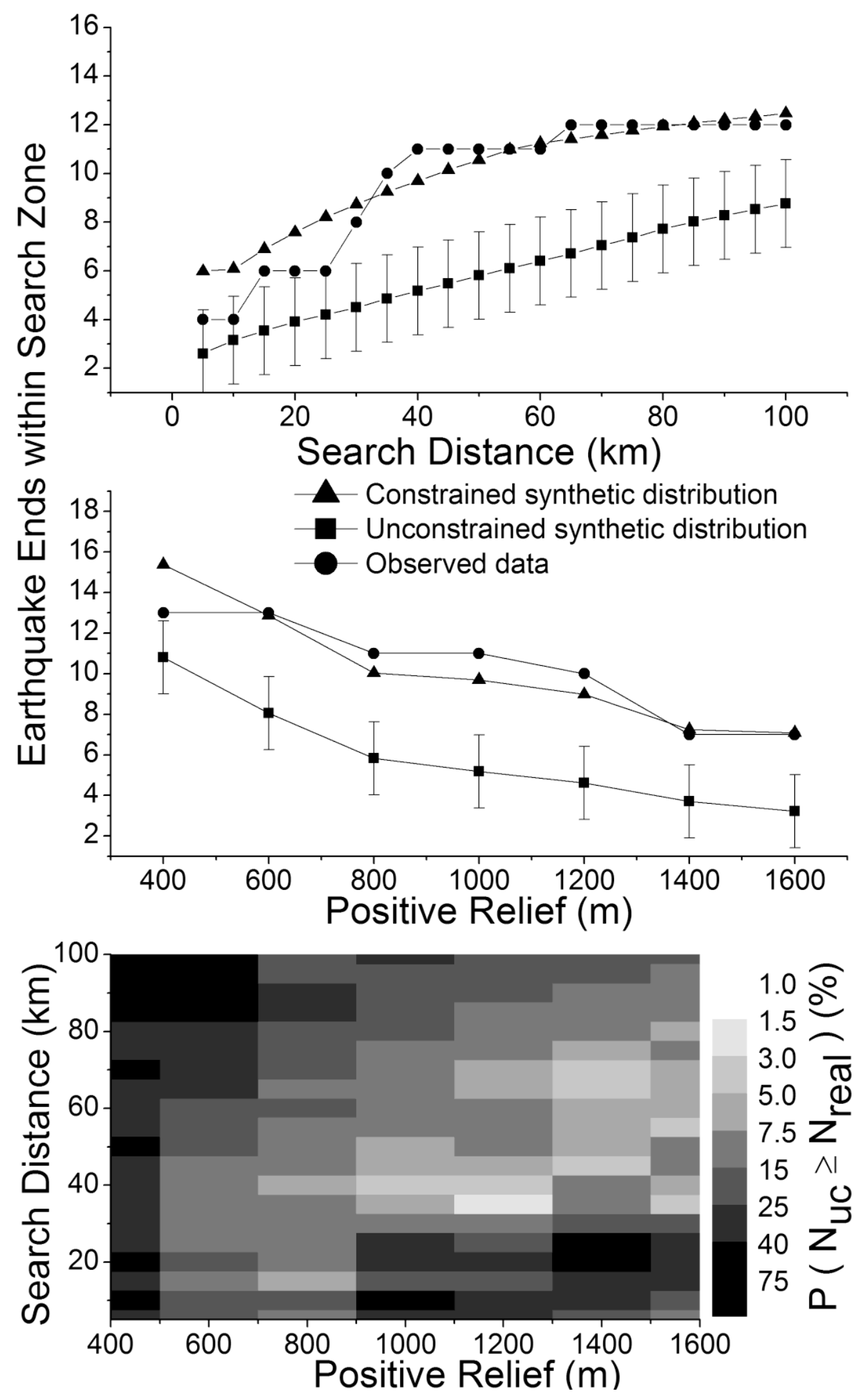

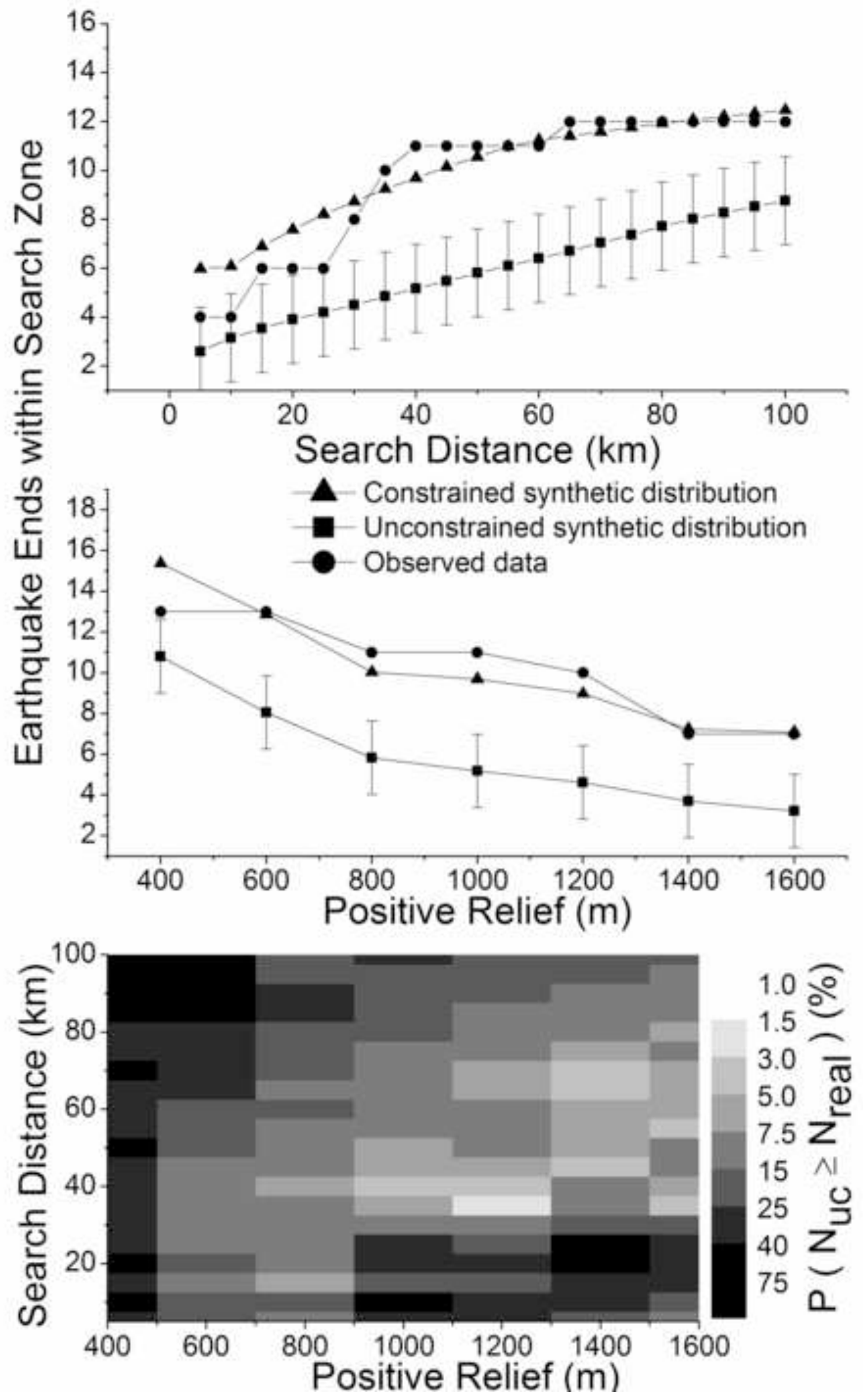